\title{
Rancang Bangun Alat Pemanas Induksi Proses Perlakuan Panas
}

\author{
Ipung Kurniawan', Bayu Aji Girawan', Imam Muasih ${ }^{3}$, Yosep Susanto ${ }^{4}$ \\ Jurusan Teknik Mesin, Politeknik Negeri Cilacap, Indonesia \\ Email: 'ipung.k.poltec@gmail.com, ${ }^{2}$ bayuaji.girawan@politeknikcilacap.ac.id, ${ }^{3}$ imamuasih@gmail.com \\ 4yosepsusanto@gmail.com
}

\begin{abstract}
ABSTRAK
Proses heat treatment yang menggunakan sistem bahan bakar sangat banyak dan waktu pemanasan cukup lama. Pemanfaatan pemanas induksi, heat treatment dapat dilakukan dengan waktu yang lebih singkat dan energi yang lebih sedikit. Tujuan dari penelitian ini; 1) Membuat desain rancangan, 2) Menghitung bagian elemen mesin, 3) Menghitung estimasi waktu dan biaya pembuatan, 4) Menguji hasil alat pemanas induksi. Metode pada penelitian ini menggunakan eksperimental. Hasil evaluasi rancangan konsep antara lain penggunaan ulir trapesium pada sistem lifter, 0,2 kilowatt daya motor, $12 \mathrm{~mm}$ diameter poros, dan ball bearing 6201 dengan umur pemakaian 0,31 tahun yang ditentukan dari perhitungan elemen mesin pada sistem pemanas induksi. Total waktu dan biaya pembuatan berkisar 3.182,06 menit dan Rp. 5.360.700,-. Hasil pengujian menunjukkan angka kekerasan raw material mild steel yang diberi perlakuan panas hardening temperatur $850{ }^{\circ} \mathrm{C}$ ditahan 45 menit meningkat dari $65,2 \mathrm{HRB}$ menjadi $84,3 \mathrm{HRB}$. Namun setelah ditempering temperatur $400{ }^{\circ} \mathrm{C}$ mengalami penurunan menjadi $69 \mathrm{HRB}$.
\end{abstract}

Kata kunci : Pemanas induksi, heat treatment, elemen mesin, kekerasan

\begin{abstract}
The heat treatment process using the fuel system is very numerous and the heating time is quite long. The use of induction heaters, heat treatment can be done with a shorter time and less energy. The purpose of this research are; (1) Make a plan design, (2) Measure the part of machine element, (3) Measure the estimation of time and design budget, (4) Test the result of induction heater machine. The method in this study uses experimental. The result of concept design evaluation, i.e., the use of trapezoid screw on the lifter system was 0,2 kilowatt of motor power, $12 \mathrm{~mm}$ of shaft diameter, and ball bearing 6201 with the age of 0,31 years which determined from the calculation of machine element on the induction heater system. The total of time for making this machine was 3.182,06 minutes and it spent $\mathrm{Rp} \mathrm{5.360.700,-.} \mathrm{The} \mathrm{result} \mathrm{of} \mathrm{test} \mathrm{shows} \mathrm{that} \mathrm{the} \mathrm{hardness}$ rate of raw material mild steel that given heat of hardening temperature of $850{ }^{\circ} \mathrm{C}$, that endured for 45 minutes increasing being $84,3 \mathrm{HRB}$. However, after being tempered temperature of $400{ }^{\circ} \mathrm{C}$ having a decrease being $69 \mathrm{HRB}$.
\end{abstract}

Keywords: Induction heater, heat treatment, machine element, hardness

\section{Pendahuluan}

Perkembangan ilmu pengetahuan dan teknologi yang semakin pesat di era globalisasi membuat kebutuhan akan penggunaan material logam dalam pembuatan alatalat dan sarana kehidupan semakin meningkat. Mulai dari peralatan yang paling sederhana sampai pada peralatan yang paling rumit, misalnya perabot rumah tangga, peralatan pemesinan, jembatan, bangunan, kendaraan, dan konstruksi pesawat terbang. Perkembangan dunia industri yang semakin maju mendorong pula kebutuhan akan material logam yang memiliki sifat yang diinginkan sesuai fungsi dan tujuan pemakaian. Sifat material logam dipilih berdasarkan sifat teknologi, sifat mekanik, sifat fisik, dan sifat kimia. Untuk membuat produk yang terbuat dari baja dengan sifat kuat, ulet, atau keras maka memerlukan perlakuan panas (heat treatment).

Heat treatment adalah proses pemanasan dan pendinginan yang terkontrol dengan maksud mengubah sifat fisik dari logam. Proses heat treatment yang menggunakan sistem yang biasa menggunakan bahan bakar sangat banyak dan waktu pemanasan yang lama. Dengan adanya pemanfaatan pemanas induksi (induction heater), heat treatment dapat dilakukan dengan waktu yang lebih singkat dan energi yang lebih sedikit. Prinsip induction heater adalah sistem pemanas dengan menggunakan induksi medan magnet yang dihasilkan dari frekuensi tinggi [1]. Hal ini dapat terjadi dikarenakan pada objek timbul arus eddy atau arus pusat yang arahnya melingkar melingkupi medan magnet yang menembus objek. Induction heater memanfaatkan rugi-rugi yang terjadi pada kumparan penginduksi. Arus eddy berperan dominan dalam proses induction heating, panas yang dihasilkan pada material sangat bergantung kepada besarnya arus eddy yang diinduksikan oleh lilitan penginduksi.

Alat heat treatment dengan pemanas induksi dapat menurunkan waktu pemanasan, menghemat energi, dan 
aman karena panas hanya setempat. Baja yang diperlakukan panas dengan temperatur dan didinginkan dengan media pendingin tertentu mempengaruhi sifat baja tersebut. Sehingga bila diketahui tingkat perbandingan sifat mekanis dengan kesesuaiannya terhadap aplikasi dan kegunaannya, maka dapat diambil suatu keputusan untuk menggunakan proses pemanasan pada temperatur tertentu dan pada media pendingin yang tepat, agar menghemat waktu dan biaya produksi. Pengkajian lebih lanjut dampak dari faktor perbedaan temperatur dan media pendingin, dapat dilakukan melalui pengujian bahan. Proses heat treatment lebih efIsien menggunakan sistem pemanas induksi. Oleh karena itu munculah gagasan untuk merancang dan membuat alat pemanas induksi dan menguji kekerasan spesimen setelah diberi perlakuan panas dengan alat tersebut.

Berdasarkan permasalahan diatas, tujuan dari penelitian ini adalah membuat desain rancangan alat pemanas induksi. Menghitung bagian elemen mesin pada mesin pemanas induksi dan estimasi waktu dan biaya pembuatan. Selain itu tujuan penelitia ini adalah menguji hasil alat pemanas induksi

\section{Tinjauan Pustaka}

Proses pemanasan roda gigi UKM menggunakan alat pemanas induksi yang telah dirancang seperti Gambar 1 . Spesimen yang sedang dipanaskan adalah roda gigi UKM diameter $62 \mathrm{~mm}$, tebal $30 \mathrm{~mm}$ dan massanya $425 \mathrm{gr}$. Pada gambar tersebut terlihat beberapa unit utama dari mesin pemanas induksi, yaitu: alat pemanas, kumparan tembaga, dan pendingin. Alat ini mampu memanaskan roda gigi hingga mencapai temperatur $800{ }^{\circ} \mathrm{C}$ dalam waktu 5-7 menit [2]

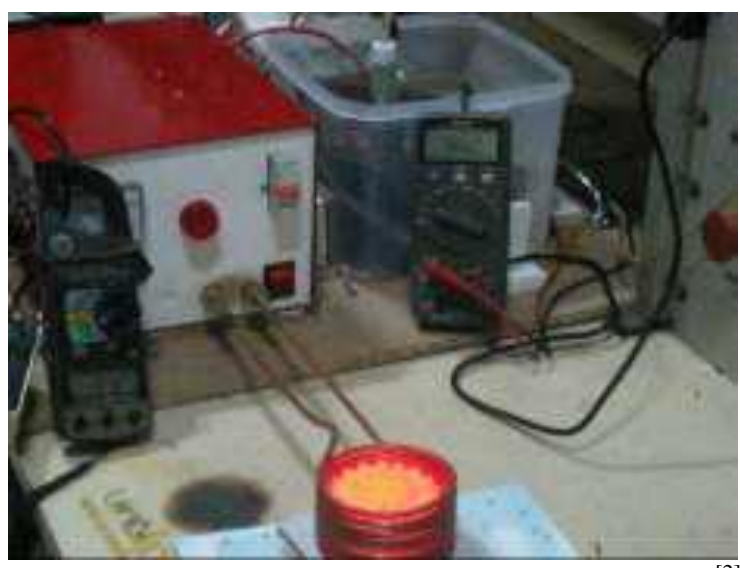

Gambar 1. Alat pemanas induksi saat bekerja ${ }^{[2]}$

Rancang bangun pemanas induksi berkapasitas 600 Watt bertujuan untuk proses perlakuan panas. Perancangan dan pembuatan pemanas induksi berdaya $600 \mathrm{~W}$ ini dilakukan dengan merangkaikan komponenkomponen utama yang terdiri atas transformator, dioda, dioda Schottky, transistor mosfet, resistor, kapasitor dan induktor. Pemanas induksi ini selanjutnya diuji coba untuk melakukan proses perlakuan permukaan pada spesimen baja AISI 1040. Temperatur pada spesimen diukur menggunakan termometer inframerah. Kumparan kerja, yang berdiameter $60 \mathrm{~mm}$, terdiri atas 6 lilitan kawat tembaga dengan diameter $3 \mathrm{~mm}$. Setelah pemanasan selama 5 menit, termometer infra merah menunjukkan temperatur maksimum $743^{\circ} \mathrm{C}$. Alat pemanas induksi dapat dilihat pada Gambar 2 [3].
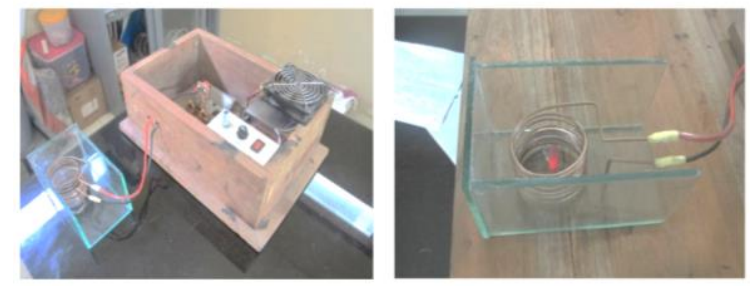

Gambar 2. Alat pemanas induksi kapasitas $600 \mathrm{~W}^{[3]}$

Penelitian pengaruh variasi temperatur pemanasan low tempering, medium tempering, dan high tempering pada medium carbon steel produksi pengecoran BaturKlaten bertujuan untuk mengetahui tingkat kekersan material. Hasil pengujian kekerasan didapatkan harga kekerasan rata-rata tertinggi pada spesimen tempering 200 ${ }^{\circ} \mathrm{C}$ sebesar 459,9 VHN dan berturut-turut menuju posisi terendah, yaitu : spesimen tempering $400{ }^{\circ} \mathrm{C}$ sebesar 308,9 VHN dan spesimen tempering $600^{\circ} \mathrm{C}$ sebesar 202,6 VHN dan paling rendah spesimen raw material sebesar 175,6 VHN dapat dilihat pada gambar 3 [4].

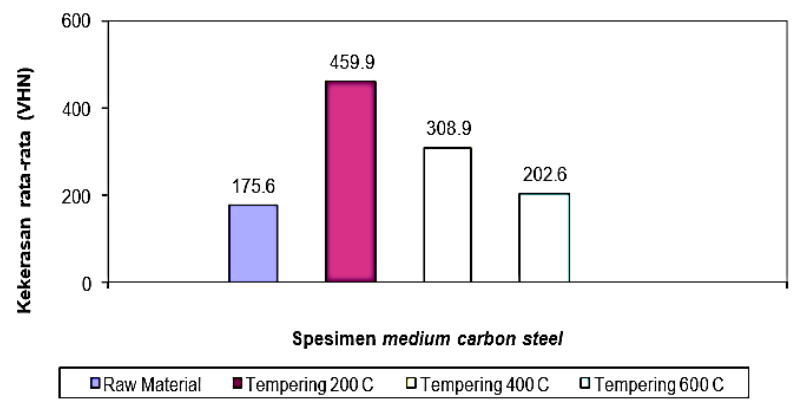

Gambar 3. Histogram perbandingan harga kekerasan rata-rata spesimen medium carbon stee ${ }^{[4]}$

\section{Induction Heating}

Induction heating adalah sistem pemanas dengan menggunakan induksi medan magnet yang dihasilkan dari frekuensi tinggi/high frequency. Hal ini dapat terjadi dikarenakan pada objek timbul arus eddy atau arus pusat yang arahnya melingkar melingkupi medan magnet yang menembus objek.

Cara kerja induction heater yaitu tegangan bolakbalik yang memiliki frekuensi tinggi yang dibangkitkan dari power modul. Frekuensi ini akan memicu sebuah komponen elektronika untuk membangkitkan daya AC yang memiliki frekuensi tinggi. Daya AC frekuensi tinggi ini yang dikirimkan ke kumparan untuk menimbulkan fluks, besar kecilnya fluks yang di bangkitkan bergantung pada luas bidang kumparan induksi yang digunakan. Hal ini dikarenakan induction heater memanfaatkan rugi-rugi yang terjadi pada kumparan penginduksi. Arus eddy berperan dominan dalam proses induction heating. Panas yang dihasilkan pada material sangat bergantung kepada besarnya arus eddy yang diinduksikan oleh lilitan penginduksi. Ketika lilitan dialiri oleh arus bolak-balik, 
maka akan timbul medan magnet di sekitar kawat penghantar. Medan magnet tersebut besarnya berubahubah sesuai dengan arus yang mengalir pada lilitan tersebut. Ilustri jalur medan magnet seperti pada Gambar 4 di bawah:

\section{Induction Heating}

Metallic bar placed in the copper coil is rapidly heated to high temperatures by induced currents from the highly concentrated magnetic field.

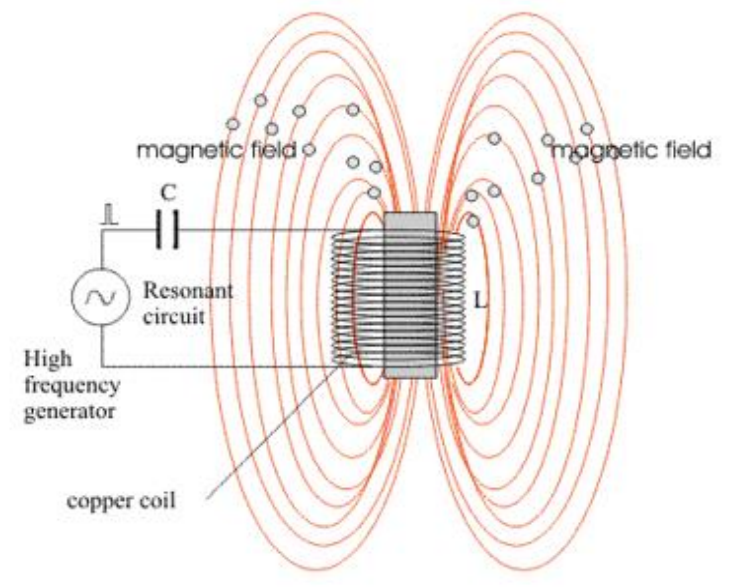

Gambar 4. Ilustrasi jalur medan magnet

Hal yang dapat menetukan banyaknya arus eddy pada logam adalah:

1. Besar medan magnet yang menginduksi logam

2. Bahan logam yang digunakan untuk menghasilkan panas. Semakin kecil hambatan jenis logam, semakin baik untuk dijadikan obyek panas logam.

3. Luas permukaan logam, makin luas permukaan logam maka makin banyak arus eddy pada permukaan logam tersebut

4. Besar frekuensi, makin besar frekuensi maka makin banyak medan magnet yang dihasilkan.

\section{Metodologi Penelitian}

Pada penelitian ini metode yang digunakan adalah metode eksperimental. Adapun tahapan pada penelitian ini dapat dirinci sebagai berikut:

\subsection{Peralatan}

Peralatan yang digunakan dalam proses desain dan perhitungan bagian elemen mesin yaitu komputer serta software gambar [5] [6]. Alat yang digunakan untuk proses pembuatan antara lain mesin gergaji, bubut, frais, gurdi, gerinda, las dan gunting plat.

\subsection{Metode Perancangan}

Metode yang digunakan dalam melakukan tahapan perancangan yaitu metode VDI 2222 [7], diperlihatkan pada Gambar 5. Pada tahap Perhitungan Elemen Mesin, dilakukan perhitungan bagian elemen mesin, seperti pada Gambar 6. Metode proses produksi alat pemanas induksi seperti pada diagram alir Gambar 7.

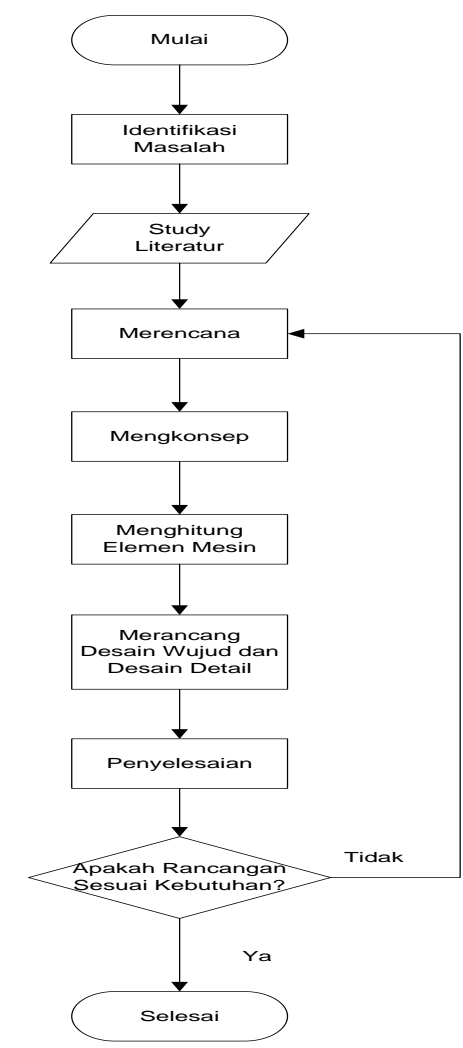

Gambar 5. Diagram alir proses perancangan

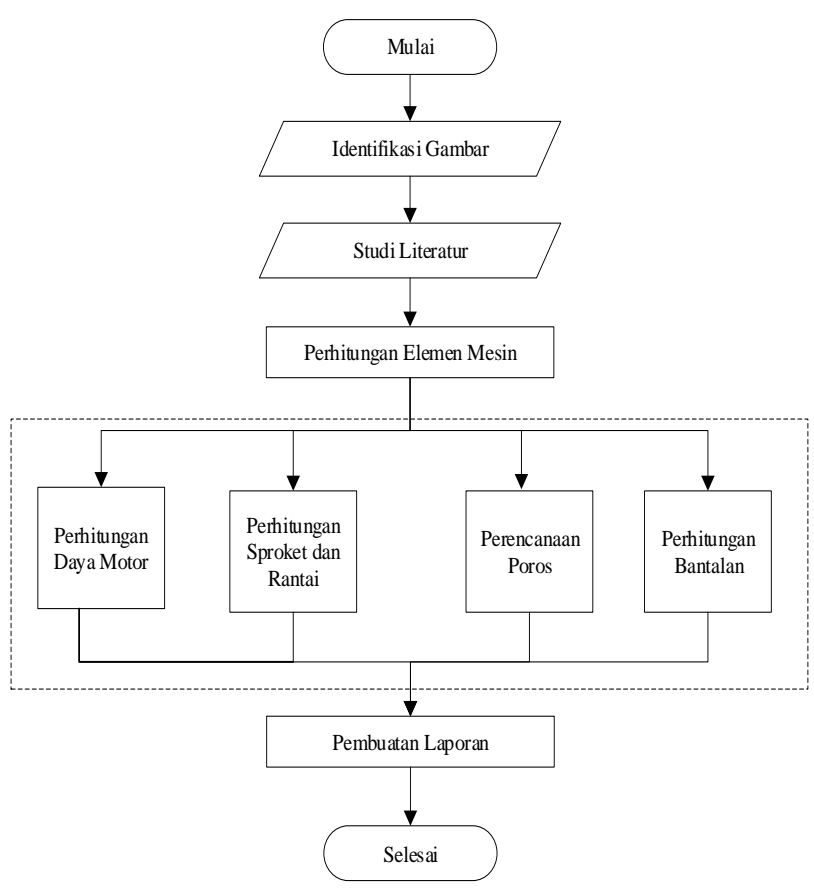

Gambar 6. Diagram perhitungan elemen mesin 


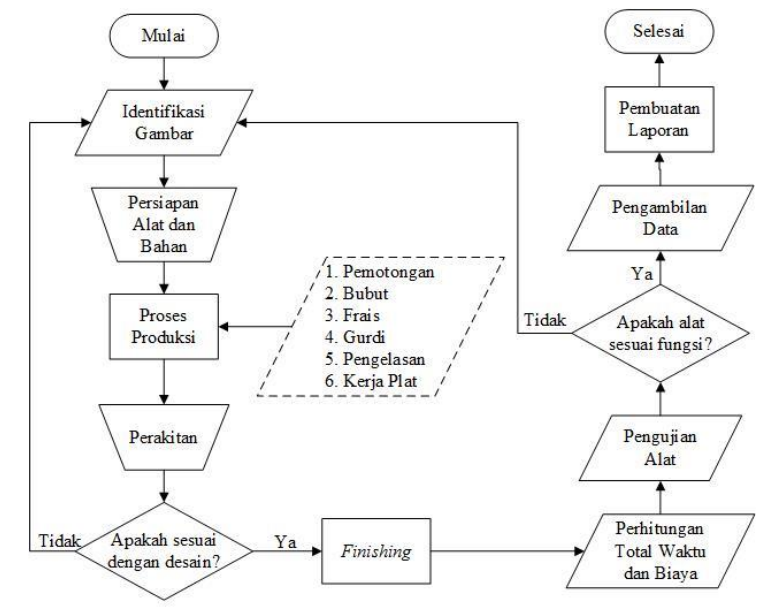

Gambar 7. Diagram alir proses produksi alat pemanas induksi.

\subsection{Metode Uji Hasil}

Metode uji hasil dengan melakukan uji kekerasan setelah dilakukan heat treatment dengan pemanas induksi. Metode uji hasil terlihat seperti pada diagram alir Gambar 8.

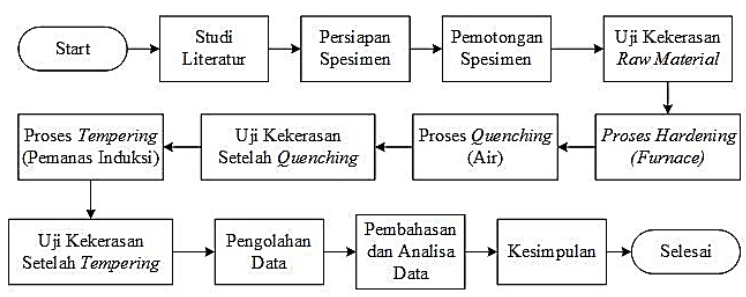

Gambar 8. Diagram alir uji hasil

\section{Hasil Dan Pembahasan}

\subsection{Hasil Perancangan}

Desain hasil perancangan alat pemanas induksi dapat dilihat pada Gambar 9a, b, c dan d.

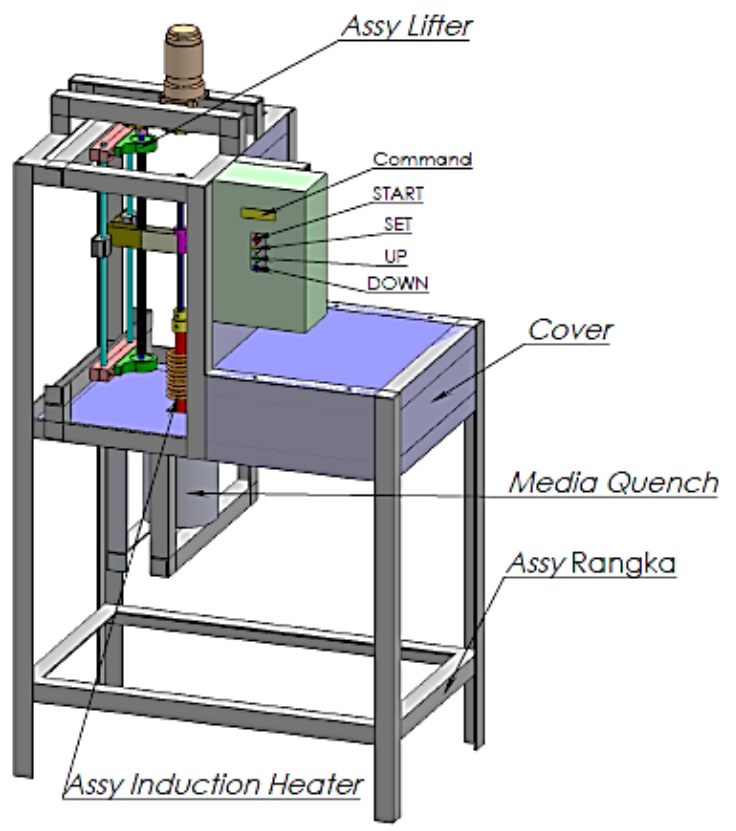

(a)

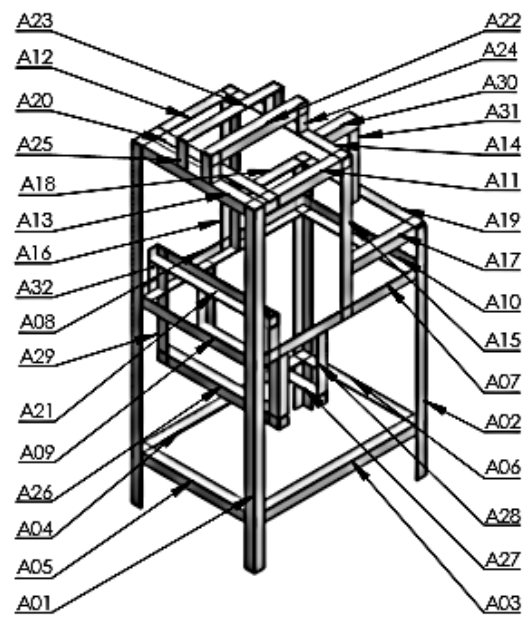

(b)

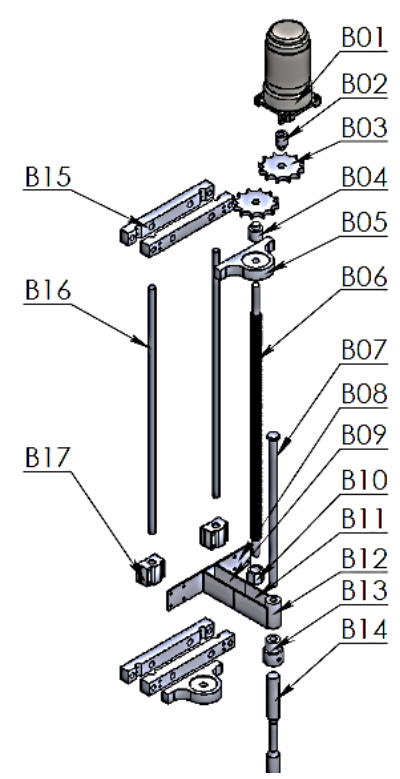

(c)

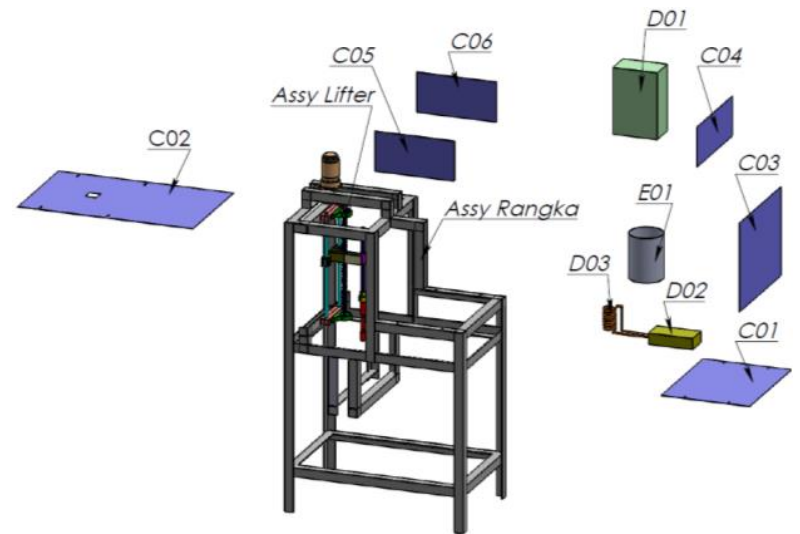

(d)

Gambar 9. (a) Alat pemanas induksi, (b) Assy rangka, (c) Assy lifter, (d) Bagian keseluruhan alat 
Nama bagian-bagian alat pemanas induksi diatas dilihat pada Tabel 1 .

Tabel 1. Nama bagian-bagian alat pemanas induksi

\begin{tabular}{|c|c|c|}
\hline $\begin{array}{c}\text { No } \\
\text { Bagian } \\
\end{array}$ & Nama Bagian & Jumlah \\
\hline A01 & Long foot & 2 \\
\hline $\mathrm{A} 02$ & Short foot & 2 \\
\hline A03 & Side frame bawah RH & 1 \\
\hline A04 & Side frame bawah LH & 1 \\
\hline A05 & Side frame bawah FR & 1 \\
\hline A06 & Side frame bawah RR & 1 \\
\hline A07 & Side frame tengah $\mathrm{RH}$ & 1 \\
\hline A08 & Side frame tengah $\mathrm{LH}$ & 1 \\
\hline A09 & Side frame tengah FR & 1 \\
\hline A10 & Side frame tengah RR & 1 \\
\hline A11 & Side frame atas RH & 1 \\
\hline A 12 & Side frame atas LH & 1 \\
\hline A13 & Side frame atas FR & 1 \\
\hline A14 & Side frame atas RR & 1 \\
\hline A 15 & Middle frame RH & 1 \\
\hline A16 & Middle frame $\mathrm{LH}$ & 1 \\
\hline A17 & Upper heater $\mathrm{RH}$ & 1 \\
\hline A18 & Upper heater $\mathrm{LH}$ & 1 \\
\hline A19 & Upper heater RR & 1 \\
\hline A20 & Frame lifter UP & 1 \\
\hline A 21 & Frame lifter UR & 1 \\
\hline A22 & Base motor RH & 1 \\
\hline A23 & Base motor LH & 1 \\
\hline A24 & Base motor FR & 2 \\
\hline A 25 & Base motor RR & 2 \\
\hline A26 & Base quenching FR & 1 \\
\hline A27 & Base quenching RR & 1 \\
\hline A28 & Base quenching RH & 2 \\
\hline A29 & Base quenching LH & 2 \\
\hline A30 & Base panel atas & 1 \\
\hline A31 & Base panel bawah & 1 \\
\hline A32 & Base lifter & 2 \\
\hline B01 & Motor listrik & 1 \\
\hline B02 & Bush motoran & 1 \\
\hline B03 & Sprocket dan rantai & 2 \\
\hline B04 & Bush transportir & 1 \\
\hline B05 & Bearing as $12 \mathrm{~mm}$ & 2 \\
\hline B06 & Poros transportir & 1 \\
\hline B07 & Poros adjuster & 1 \\
\hline B08 & Lengan slide bearing & 1 \\
\hline B09 & Lengan mur & 2 \\
\hline B10 & Mur transportir & 1 \\
\hline B11 & Lengan adjuster & 2 \\
\hline B12 & Adjuster & 1 \\
\hline B13 & Cekam spesimen & 1 \\
\hline B14 & Spesimen & 1 \\
\hline B15 & Cekam sliding & 4 \\
\hline B16 & Poros sliding & 2 \\
\hline B17 & Slide bearing & 2 \\
\hline $\mathrm{C} 01$ & Cover up & 1 \\
\hline $\mathrm{C} 02$ & Cover down & 1 \\
\hline
\end{tabular}

\begin{tabular}{clc}
\hline $\begin{array}{c}\text { No } \\
\text { Bagian }\end{array}$ & \multicolumn{1}{c}{ Nama Bagian } & Jumlah \\
\hline C03 & Cover LH & 1 \\
C04 & Cover RH & 1 \\
C05 & Cover FR & 1 \\
C06 & Cover RR & 1 \\
D01 & Panel box & 1 \\
D02 & Modul heater & 1 \\
D03 & Induction coil & 1 \\
E01 & Kaleng media quench & 1 \\
\hline
\end{tabular}

\subsection{Perhitungan Elemen Mesin}

Untuk menentukan daya motor yang digunakan pada sistem pemanas induksi ini dapat menggunakan rumus sebagai berikut:

1). Menghitung gaya

Masanya adalah sebesar $2 \mathrm{~kg}$

$$
\begin{aligned}
\boldsymbol{F} & =\mathbf{m} \times \mathbf{g} \\
& =2 \times 10 \\
& =20 \mathrm{~N}
\end{aligned}
$$

2). Menghitung torsi

$$
\begin{aligned}
& \text { Jari-jari sprocket } 0.0245 \mathrm{~m} \\
& \begin{aligned}
\mathbf{T} & =\mathbf{F} \times \mathbf{r} \\
& =20 \times 0.0245 \\
& =0.49 \mathrm{~N} . \mathrm{m}
\end{aligned}
\end{aligned}
$$

3). Menghitung sudut kisar ulir

Ulir trapesium $3 / 4$ inchi dengan $\mathrm{L}=0.1667 \mathrm{in}$, dan diameter nominal 0.6424 in.

$$
\begin{aligned}
\mathbf{I} & =\operatorname{tg}^{-1} \frac{\mathbf{L}}{\pi \mathrm{Dp}} \\
& =\tan ^{-1} \frac{0.1667}{2.018159121} \\
& =4.72^{\mathrm{o}}
\end{aligned}
$$

4). Menghitung beban yang digerakan Beban total diketahui $2.7 \mathrm{~kg}$.

$$
\begin{aligned}
\boldsymbol{F} & =\mathbf{m} \times \mathbf{g} \\
& =2.7 \times 10 \\
& =27 \mathrm{~N}
\end{aligned}
$$

5). Menghitung torsi naik

Koefisien gesek sebesar 0.15

$$
\begin{aligned}
\boldsymbol{T}_{\boldsymbol{u}} & =\frac{\mathbf{F D}_{p}}{\mathbf{2}}\left[\frac{(\cos \mathbf{t} \boldsymbol{t a n I}+\boldsymbol{f})}{(\cos \mathbf{f}-\boldsymbol{f} \tan \mathrm{I})}\right] \\
& =\frac{27 \times 0.016}{2}\left[\frac{(0.968 \times 0.0826)+0.15}{0.968-(0.15 \times 0.0826)}\right] \\
& =0.052 \mathrm{~N} . \mathrm{m}
\end{aligned}
$$

6). Menghitung torsi turun

$$
\begin{aligned}
\boldsymbol{T}_{\boldsymbol{d}} & =\frac{\mathrm{FD}_{p}}{2}\left[\frac{(\boldsymbol{f}-\cos \mathrm{f} \tan I)}{(\operatorname{cosf}+\boldsymbol{f} \tan I)}\right] \\
& =\frac{27 \times 0.016}{2}\left[\frac{0.15-(0.968 \times 0.0826)}{0.968+(0.15 \times 0.0826)}\right] \\
& =0.015 \mathrm{~N} . \mathrm{m}
\end{aligned}
$$

7). Kecepatan lifter 
Kecepatan lifter yang diinginkan $0.02 \mathrm{~m} / \mathrm{s}$

Sehingga kecepatan putar motor dapat dihitung, dengan pitch ulir trapesium $0.004 \mathrm{~m}$

$$
\begin{aligned}
\mathrm{n} & =\frac{0.02 \mathrm{~m}}{\mathrm{~s}} \frac{1 \text { putaran }}{0.004 \mathrm{~m}} \frac{60 \mathrm{~s}}{\text { menit }} \\
& =300 \mathrm{rpm}
\end{aligned}
$$

8). Menentukan torsi total

$\mathrm{T}$ total $=\mathrm{T}_{\mathrm{u}}+\mathrm{T}$

$$
\begin{aligned}
& =0.052+0.49 \\
& =0.54 \mathrm{~N} . \mathrm{m}
\end{aligned}
$$

9). Menentukan daya motor

$$
\begin{aligned}
\mathbf{P} & =\mathbf{T} \mathbf{x} \boldsymbol{\omega} \\
& =\frac{\text { torsi }(\mathrm{Nm}) \times 2 \pi \times \mathrm{n}}{60000} \\
& =\frac{0.54(\mathrm{Nm}) \times 2 \pi \times 300}{60000} \\
& =0.017 \mathrm{KW}
\end{aligned}
$$

Untuk kerhitungan sprocket dan rantai dapat dihitung dengan cara:

1). Menghitung perbandingan sprocket

$$
\begin{aligned}
\mathbf{V r} & =\frac{n_{1}}{n_{2}}=\frac{z_{2}}{z_{1}} \\
n_{2} & =\frac{Z_{1} \times n_{1}}{Z_{2}} \\
& =\frac{12 \times 300}{12} \\
& =300 \mathrm{rpm}
\end{aligned}
$$

2). Menentukan jumlah mata rantai

Nomor rantai yang digunakan adalah 40, dengan pitch $12.7 \mathrm{~mm}$, dan jarak rencana antar sumbu $100 \mathrm{~mm}$.

$$
\begin{aligned}
\boldsymbol{L}_{\boldsymbol{p}} & =\frac{\boldsymbol{Z}_{1}+Z_{2}}{\mathbf{2}}+\frac{\mathbf{C} \boldsymbol{C}}{\boldsymbol{p}}+\frac{(\boldsymbol{Z 2}-\boldsymbol{Z 1})^{2}}{2 \pi} \frac{\boldsymbol{p}}{\boldsymbol{C}} \\
& =\frac{12+12}{2}+\frac{2 \times 100}{12.7}+\frac{(12-12)^{2}}{2 \pi} \frac{12.7}{100} \\
& =28 \text { mata rantai }
\end{aligned}
$$

3). Menentukan jarak antar sumbu

$$
\begin{aligned}
C & =\frac{p}{4}\left\{\left(L_{p}-\frac{Z_{1+Z_{2}}}{2}\right)+\sqrt{\left(L_{p}-\frac{z_{1}+Z_{2}}{2}\right)^{2}-8\left(\frac{z_{2}-Z_{1}}{2 \pi}\right)^{2}}\right\} \\
& =\frac{12.7}{4}\left\{\left(28-\frac{12+12}{2}\right)+\sqrt{\left(28-\frac{12+12}{2}\right)^{2}-8\left(\frac{12-12}{2 \pi}\right)^{2}}\right\} \\
& =101.6 \mathrm{~mm}
\end{aligned}
$$

4). Menghitung panjang rantai

$$
\begin{aligned}
\boldsymbol{L} & =\boldsymbol{L}_{\boldsymbol{p}} \times \boldsymbol{p} \\
& =28 \times 12.7 \\
& =355.6 \mathrm{~mm}
\end{aligned}
$$

5). Menghitung diameter nominal sprocket

$$
\begin{aligned}
\boldsymbol{D} & =\boldsymbol{p} \operatorname{cosec} \frac{\mathbf{1 8 0 0}}{\boldsymbol{T}} \\
& =12.7 \operatorname{cosec} \frac{180 \mathrm{o}}{12} \\
& =49.02 \mathrm{~mm}
\end{aligned}
$$

6). Menentukan besar defleksi

$$
\begin{aligned}
e & =2 \% \times C \\
& =2 \% \times 102 \\
& =2,04 \mathrm{~mm}
\end{aligned}
$$

7). Menghitung kecepatan rantai

$$
\begin{aligned}
\boldsymbol{v} & =\frac{\boldsymbol{p . \boldsymbol { Z } _ { \mathbf { 1 . n } \mathbf { 1 } }}}{\mathbf{1 0 0 0 \times \mathbf { 6 0 }}} \\
& =\frac{12.7 \times 12 \times 300}{1000 \times 60} \\
& =0.76 \mathrm{~m} / \mathrm{s}
\end{aligned}
$$

8). Menghitung gaya tarik pada rantai

$$
\begin{aligned}
\boldsymbol{F} & =\frac{\boldsymbol{P d}}{\boldsymbol{v}} \\
& =\frac{17}{0.76} \\
& =22.37 \mathrm{~N}
\end{aligned}
$$

\subsection{Perencanaan poros transportir}

1). Perhitungan daya poros

Pada perhitungan daya poros ini akan diperlukan daya maksimum sebagai daya rencana dengan faktor koreksi $f_{c}$ sebesar 1,2 seperti tertera pada tabel faktor koreksi ${ }^{[5]}$. Sehingga besar daya rencana $P_{d}$ dapat dihitung menggunakan persamaan sebagai berikut.

$$
\begin{aligned}
\boldsymbol{P}_{\boldsymbol{d}} & =\boldsymbol{f}_{\boldsymbol{c}} \times \mathbf{P} \\
& =1,2 \times 0,017 \mathrm{~kW} \\
& =0,0204 \text { kilowatt }
\end{aligned}
$$

2). Menghitung moment puntir yang terjadi

$$
\begin{aligned}
\boldsymbol{T} & =\mathbf{9 . 7 4} \times \mathbf{1 0}^{\mathbf{5}} \frac{\boldsymbol{P}_{\boldsymbol{d}}}{\boldsymbol{n}_{\mathbf{2}}} \\
& =9.74 \times 10^{5} \frac{0,2 \mathrm{~kW}}{300 \mathrm{rpm}} \\
& =642.8 \mathrm{~kg} . \mathrm{mm}
\end{aligned}
$$

\section{3). Perhitungan tegangan geser}

Pada perhitungan tegangan geser ini $\tau_{a}$ dihitung atas dasar batas kelelahan puntir yang besarnya diambil $40 \%$ dari batas kelelahan tarik yang besarnya kira-kira $45 \%$ dari kekuatan tarik $\sigma_{B}\left(\mathrm{~kg} / \mathrm{mm}^{2}\right)$. Jadi, batas kelelahan puntir adalah $18 \%$ dari kekuatan tarik $\sigma_{B}$, sesuai dengan standar ASME. Untuk harga $18 \%$ ini faktor keamanan diambil sebesar $1 / 0.18=5.6$. Harga 5.6 ini diambil untuk bahan SF dengan kekuatan yang dijamin, dan 6.0 untuk bahan S-C dengan pengaruh masa, dan baja paduan. Faktor ini dinyatakan dengan $S f_{1}$. Selanjutnya poros tersebut akan dibuat bertangga, karena pengaruh konsentrasi tegangan cukup besar. Untuk memasukkan pengaruh-pengaruh ini dalam perhitungan diambil faktor yang dinyatakan sebagai $S f_{2}$ dengan harga sebesar 1.3 sampai $3.0^{[5]}$.

Untuk bahan poros yang akan digunakan pada transportir adalah bahan poros baja jenis S45C dengan kekuatan tarik $\sigma_{B}=58 \mathrm{Kg} / \mathrm{mm}^{2}, S f_{1}$ (faktor keamanan) yang digunakan adalah sebesar 6,0 (untuk bahan S-C dengan pengaruh masa, dan baja paduan), dan $S f_{2}$ (konsentrasi tegangan) yang digunakan adalah 1.3 
maka perhitungan tegangan geser yang diizinkan adalah sebagai berikut.

$$
\begin{aligned}
\boldsymbol{\tau}_{\boldsymbol{a}} & =\frac{\boldsymbol{\sigma}_{\boldsymbol{B}}}{\left(\boldsymbol{S}_{\mathbf{1}} \times \boldsymbol{S}_{\boldsymbol{2}}\right)} \\
& =\frac{58 \mathrm{Kg} / \mathrm{mm}^{2}}{(6.0 \times 1.3)} \\
= & 7.4 \mathrm{~kg} / \mathrm{mm}^{2}
\end{aligned}
$$

\section{4). Menghitung diameter poros}

Keadaan momen puntir itu sendiri harus ditinjau. Faktor koreksi yang dianjurkan oleh ASME juga dipakai disini. Ditentukan besarnya nilai faktor koreksi tumbukan $\left(K_{t}\right)$, diambil nilai 1 seperti pada tabel faktor koreksi tumbukan $\left(K_{t}\right)$, diperlihatkan pada Tabel 2 .

Tabel 2. Faktor koreksi tumbukan

\begin{tabular}{lc}
\hline Beban yang dikenakan & $\boldsymbol{K}_{\boldsymbol{t}}$ \\
\hline Halus & 1,0 \\
Sedikit Kejutan atau Tumbukan & $1,0-1,5$ \\
Kejutan atau Tumbukan Berat & $1,5-3,0$ \\
\hline
\end{tabular}

Meskipun dalam perkiraan sementara bahwa beban hanya terdiri atas momen puntir saja, perlu ditinjau pula apakah ada kemungkinan pemakaian dengan beban lentur dimasa mendatang. Jika memang diperkirakan akan terjadi pemakaian dengan beban lentur maka dapat dipertimbangkan dengan faktor $\mathrm{C}_{\mathrm{b}}$ yang harganya antara 1,2 sampai 2,3. (Jika diperkirakan tidak akan terjadi pembebanan lentur maka $\mathrm{C}_{\mathrm{b}}$ diambil 1,0$)^{[8]}$

$d_{s} \geqq\left[\frac{5,1}{\tau_{a}} K_{t} \mathrm{Cb} T\right]^{1 / 3}$

$d_{s} \geqq\left[\frac{5,1}{7.4} 1.5 \times 2.3 \times 642.8\right]^{1 / 3}$

$d_{s} \geqq 11.5 \mathrm{~mm}$

jadi diameter minimum dari transportir adalah $11.5 \mathrm{~mm}$, dan diameter yang dipakai adalah $12 \mathrm{~mm}$

a. Perhitungan umur bantalan

Bantalan yang dipakai pada alat heat treatment dengan pemanas induksi ini menggunakan spesifikasi sebagai berikut :

- Nomor Bantalan

$=6201$

- Diameter dalam

$=\varnothing 12 \mathrm{~mm}$

- Diameter luar

- Lebar bearing

$=\varnothing 32 \mathrm{~mm}$

Jari-jari bearing

$=10 \mathrm{~mm}$

$=1 \mathrm{~mm}$

- Kapasitas Nominal dinamis spesifik C $\quad(\mathrm{kg})=535$ $\mathrm{kg}$

1). Perhitungan beban ekivalen

Diketahui beban radial sebesar $2.2 \mathrm{~kg}$, dan beban aksial sebesar $4.7 \mathrm{~kg}$.

$$
\begin{aligned}
\mathbf{P r} & =\mathbf{X} \cdot \mathbf{V} \cdot \mathbf{F r}+\mathbf{Y} \cdot \mathbf{F a} \\
& =0.56 .1 \cdot 2.2+1.45 .4 .7 \\
& =8.05 \mathrm{~kg}
\end{aligned}
$$

$$
\begin{aligned}
& \text { 2). Faktor kecepatan } \\
& \begin{aligned}
f_{n} & =\left[\frac{[33,3]}{n_{2}}\right]^{1 / 3} \\
& =\left[\frac{[33,3]}{300}\right]^{1 / 3} \\
& =0.48 \mathrm{rad}
\end{aligned}
\end{aligned}
$$

3). Faktor umur

$$
\begin{aligned}
f_{h} & =f_{n} \frac{C}{P_{r}} \\
& =0.48 \frac{535}{8.05} \\
& =31.9
\end{aligned}
$$

4). Menentukan umur nominal bantalan

$$
\begin{aligned}
L_{h} & =500 . f_{h}{ }^{3} \\
& =500.31 .9^{3} \\
& =16.230 .880 \text { putaran }
\end{aligned}
$$

1 hari bekerja 8 jam

\begin{tabular}{|c|c|c|c|}
\hline No & Komponen & $\begin{array}{c}\text { Waktu } \\
\text { produktif }\end{array}$ & $\begin{array}{c}\text { Waktu non } \\
\text { produktif }\end{array}$ \\
\hline 1 & Besi siku & & 100 \\
\hline 2 & Besi as & & 42 \\
\hline 3 & $\begin{array}{l}\text { Besi kotak } \\
\text { pejal }\end{array}$ & 88,05 & 42 \\
\hline 4 & Besi plat & & 56 \\
\hline \multicolumn{2}{|c|}{$\begin{array}{l}\text { Total waktu } \\
\text { pemotongan }\end{array}$} & \multicolumn{2}{|c|}{$\begin{array}{r}240 \\
328,05 \text { menit }\end{array}$} \\
\hline
\end{tabular}

$\mathrm{N}=5 \mathrm{rad} / \mathrm{s} \times 3600 \mathrm{menit}=18000 \mathrm{rad} / \mathrm{h}$

Maka 1 hari bekerja dalam 8 jam $\times 18000 \mathrm{rph}=144000$

Jadi umur nominal bantalan adalah:

$$
\begin{aligned}
L_{h} & =\frac{16.230 .880}{144000} \\
& =0.31 \text { tahun }
\end{aligned}
$$

b. Perhitungan Waktu Proses Produksi

1) Perhitungan waktu proses pemotongan

Proses pemotongan komponen untuk pembuatan alat pemanas induksi terdapat beberapa material yang berbeda yaitu besi siku $40 \times 40 \times 4 \mathrm{~mm}$, besi as ST41 $\emptyset 25,4 \mathrm{~mm}$, besi kotak pejal $200 \times 123 \times 25 \mathrm{~mm}$, dan plat lebar $40 \mathrm{~mm}$ tebal $4 \mathrm{~mm}$. Hasilnya diperlihatkan pada Tabel 3 dan Tabel 4.

Tabel 3. Waktu produktif proses pemotongan

\begin{tabular}{lccccc}
\hline Benda & $\begin{array}{c}\mathbf{A} \\
\left(\mathbf{c m}^{2}\right)\end{array}$ & $\begin{array}{c}\text { t/ A } \\
\mathbf{d t} / \mathbf{c m} \mathbf{2}\end{array}$ & jumlah & $\begin{array}{c}\mathbf{t} \\
\text { potong } \\
\text { (detik) }\end{array}$ & $\begin{array}{c}\mathbf{t} \\
\text { potong } \\
(\mathbf{m e n i t})\end{array}$ \\
\hline Besi siku & 3,04 & 0,12 & 39 & 898 & 14,96 \\
$\begin{array}{l}\text { Besi as } \\
\text { Besi }\end{array}$ & 5,06 & 0,67 & 7 & 1435 & 23,92 \\
kotak & & & & & \\
pejal & 50 & 0,12 & 3 & 1102 & 48 \\
Besi plat & 1,6 & 0,12 & 6 & 70 & 1,17 \\
\hline \multicolumn{5}{l}{ Total waktu produktif pemotongan } & $\mathbf{8 8 , 0 5}$ \\
\hline
\end{tabular}

Tabel 4. Waktu proses pemotongan 
Jadi, jumlah waktu yang dibutuhkan untuk proses pemotongan adalah 328,05 menit $\approx \mathbf{5 , 4 7}$ jam.

2) Perhitungan waktu proses bubut

Proses pembuatan komponen ada yang dilakukan dengan proses pembubutan. Waktu produktif pembubutan dapat dilihat pada tabel 5 dan total waktu pembubutan dapat dilihat pada tabel 6 .

Tabel 5. Waktu produktif proses bubut

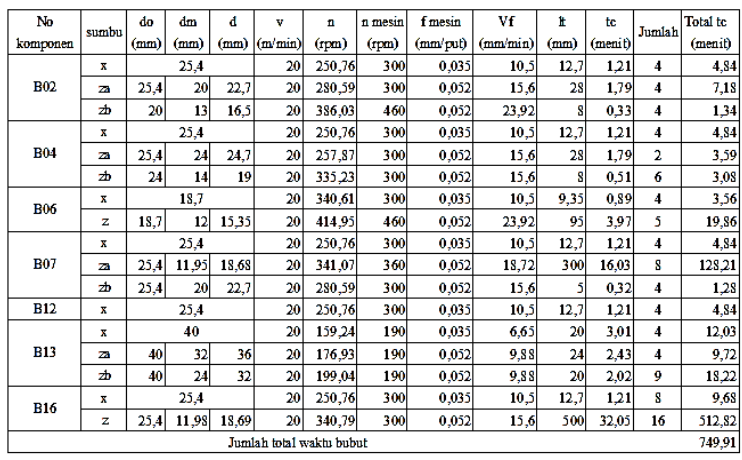

Tabel 6. Waktu proses pembubutan

\begin{tabular}{llcc}
\hline No & Komponen & $\begin{array}{c}\text { Waktu } \\
\text { produktif }\end{array}$ & $\begin{array}{c}\text { Waktu non } \\
\text { produktif }\end{array}$ \\
\hline 1 & B02 & & 45 \\
2 & B04 & & 45 \\
3 & B06 & 749,91 & 71 \\
4 & B07 & 66 \\
5 & B12 & 44 \\
6 & B13 & 71 \\
7 & B16 & 141 \\
\multicolumn{2}{c}{ Total waktu } & \multicolumn{2}{c}{482,99} \\
\multicolumn{2}{c}{ pembubutan } & 1232,9 menit \\
\hline
\end{tabular}

Jadi, jumlah waktu yang dibutuhkan untuk proses bubut adalah 1232,9 menit $\approx \mathbf{2 0 , 5 5}$ jam.

3) Perhitungan waktu proses frais

Proses pembuatan komponen ada yang dilakukan dengan proses frais. Waktu produktif proses frais dapat dilihat pada tabel 7 dan total waktu frais dapat dilihat pada tabel 8 .

Dihasilkan jumlah waktu yang dibutuhkan untuk proses frais adalah 344,68 menit $\approx \mathbf{5 , 7 4}$ jam seperti pada tabel 8 .

Tabel 7. Waktu produktif proses frais

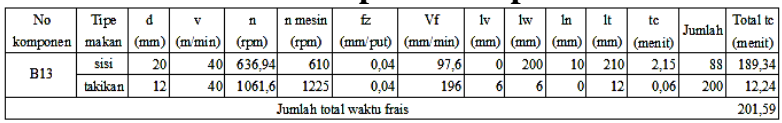

Tabel 8. Waktu proses frais

\begin{tabular}{|c|c|c|}
\hline No & Langkah Pekerjaan & $\begin{array}{r}\text { Waktu } \\
\text { (menit) }\end{array}$ \\
\hline $\mathbf{A}$ & B15 Cekam sliding & \\
\hline 1 & Periksa gambar dan ukuran & 32 \\
\hline 2 & $\begin{array}{l}\text { Mempersiapkan peralatan } \\
\text { mesin }\end{array}$ & 5 \\
\hline 3 & $\begin{array}{l}\text { Penandaan pada } \\
\text { bahan/material }\end{array}$ & 24 \\
\hline 4 & $\begin{array}{l}\text { Memasang pahat frais dan } \\
\text { mengatur kecepatan }\end{array}$ & 10 \\
\hline 5 & Mengatur posisi pahat frais & 32 \\
\hline 6 & Pemasangan benda kerja & 16 \\
\hline 7 & Waktu pengefraisan sisi & 201,44 \\
\hline 8 & Waktu pengefraisan takikan & 12,24 \\
\hline 9 & Pemeriksaan akhir & 12 \\
\hline \multicolumn{2}{|c|}{ Jumlah waktu frais B15 } & 344,68 \\
\hline
\end{tabular}

4) Perhitungan waktu proses gurdi

Proses pembuatan komponen ada yang dilakukan dengan proses gurdi. Waktu produktif proses gurdi dapat dilihat pada tabel 9 dan total waktu gurdi dapat dilihat pada tabel 10 .

Tabel 9. Waktu produktif proses gurdi

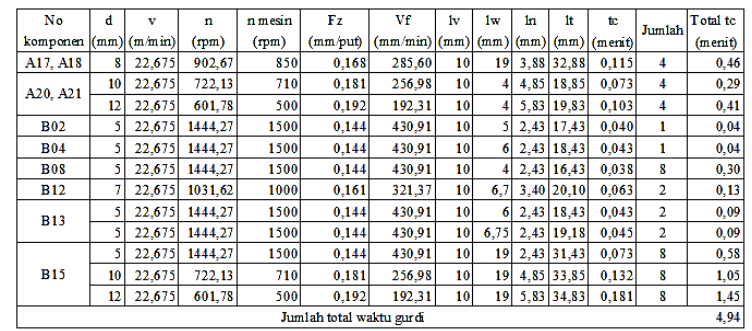

Tabel 10. Waktu proses gurdi

\begin{tabular}{|c|c|c|c|}
\hline No & Komponen & $\begin{array}{c}\text { Waktu } \\
\text { produktif }\end{array}$ & $\begin{array}{c}\text { Waktu non } \\
\text { produktif }\end{array}$ \\
\hline 1 & A17, A18 & \multirow{8}{*}{4,94} & 31 \\
\hline 2 & A20, A21 & & 61 \\
\hline 3 & B02 & & 23 \\
\hline 4 & B04 & & 23 \\
\hline 5 & B08 & & 26 \\
\hline 6 & B12 & & 26 \\
\hline 7 & B13 & & 32 \\
\hline 8 & B15 & & 125 \\
\hline \multicolumn{2}{|c|}{ Total waktu } & \multirow{2}{*}{\multicolumn{2}{|c|}{346,99}} \\
\hline & gurdi & & \\
\hline
\end{tabular}

Jadi, jumlah waktu yang dibutuhkan waktu proses gurdi adalah 351,93 menit $\approx \mathbf{6 , 3 7}$ jam.

Hasil perhitungan waktu pengelasan, waktu proses perakitan (assembly), dan waktu proses finishing diperlihatkan pada Tabel 11, Tabel 12, dan Tabel 13. 
DOI: 10.35970/accurate.v1i1.162

Paramita, 1997.

design. Eurasia, 2005.

[7] R. S. Khurmi and J. K. Gupta, A textbook of machine 